\title{
O marxismo fora do lugar
}

\author{
Alvaro Bianchi *
}

No queremos, ciertamente, que el socialismo sea en América calco y copia. Debe ser creación heroica. Tenemos que dar vida, con nuestra propia realidad, en nuestro propio lenguaje, al socialismo indoamericano. He aquí una misión digna de una generación nueva. (MARIÁTEGUI, 1987, p. 249.)

\section{Resumo}

$\mathrm{O}$ artigo discute a dificuldade presente para o desenvolvimento de um marxismo latino-americano. Essa dificuldade pode remeter à própria obra de Karl Marx e Friedrich Engels e à filosofia da história que se faz presente em alguns momentos dessa obra. A análise da situação irlandesa e da comuna rural russa, entretanto, permitiram a esses autores e, principalmente a Marx romper com essa filosofia da história. A seguir o artigo discute uma tentativa de interpretação da América Latina e particularmente do Brasil com base na obra de Marx: aquela desenvolvida no âmbito do chamado Seminário d'O Capital. Neste Seminário gestou-se uma forma de apropriação da obra de Marx na qual se destacavam seus aspectos metodológicos. Apesar das importantes contribuições dos autores vinculados a esse seminário, dentre os quais Fernando Henrique Cardoso e sua análise das situações de dependência, essa apropriação da obra de Marx revelou claros limites. Argumenta-se, por último a necessidade do marxismo construir uma unidade profunda entre teoria e prática, pesquisa teórica e pesquisa empírica para superar os impasses da interpretação da América Latina.

Palavras-chave: Marxismo, Teoria da Dependência, intercâmbio desigual, América Latina.

* Professor do Departamento de Ciência Política da Universidade Estadual de Campinas (Unicamp) e diretor adjunto do Arquivo Edgard Leuenroth - Centro de Pesquisa e Documentação Social. Endereço eletrônico: albianchi@terra.com.br. 
E mbora a presença de Marx seja incontornável em nosso subcontinente, a existência de um pensamento marxista latinoamericano deveria surpreender dadas as dificuldades que Marx e Engels demonstraram para apreender a realidade da América Latina. Em alguns momentos chegaram até mesmo a adotar uma visada eurocêntrica que repercutia uma filosofia da história de corte hegeliano. Se bem fosse Engels e não Marx quem estivesse mais preso a essa filosofia, o que se evidencia nas repetidas vezes em que este fez referência aos "povos sem história", ela não deixava de se fazer presente no autor d'O Capital.

Embora o volume de textos de Marx sobre a América Latina seja maior do que se pensava há algumas décadas, não é possível encontrar nesses textos senão indicações muito rudimentares para se pensar a América Latina. Nesse ponto contrasta, tanto pelo volume como pela originalidade, a atenção dedicada por Marx à análise da história dos Estados Unidos. Aí está um ponto sobre o qual o pensamento crítico deveria se debruçar com mais atenção. A comparação entre as análises de Marx e Engels referentes aos Estados Unidos e à América Latina evidencia as dificuldades encontradas por ele para tratar desta última.

Essa dificuldade se expressa na diferença existente entre o tratamento dispensado por Marx ao presidente dos Estados Unidos Abraham Lincoln e a Simon Bolívar, libertador da América. Em uma carta a Lincoln redigida por Marx e publicada em dezembro de 1864, a Associação Internacional de Trabalhadores (AIT) congratulava "o povo americano pela sua reeleição por larga maioria". E acrescentava: "Se a resistência ao Poder Escravista era a moderada palavra-de-ordem de sua primeira eleição, o grito de batalha triunfal de sua reeleição é Morte à Escravidão.” (MECW, 20, p. 19). ${ }^{1} \mathrm{E}$ concluía afirmando que os trabalhadores da Europa consideravam um "augúrio da época em que entramos que tenha correspondido a Abraham Lincoln, o determinado filho da classe trabalhadora, liderar seu país através de uma guerra sem precedentes com o propósito de

1 A carta não deixava de saudar o nascimento em solo americano, um século antes da "ideia de uma grande República democrática", da "primeira declaração dos Direitos do Homem" e do "primeiro grande impulso à revolução européia do século XVIII". 
resgatar uma raça acorrentada e reconstruir o mundo social." (idem, p. 20.) A admiração de Marx reaparece na carta que a AIT enviou ao presidente Andrew Johnson, após o assassinato de Lincoln. ${ }^{2} \mathrm{~A}$ missiva concluía afirmando que o povo americano "ao iniciar a nova era de emancipação do trabalho (...) atribuiu as responsabilidades de liderança a dois homens do trabalho - o primeiro Abraham Lincoln e o outro Andrew Johnson." (idem, p. 100).

O contraste com sua apreciação de Simon Bolívar é imenso e chama a atenção. Ele se revela em toda sua amplitude em um artigo redigido em 1858, para The New American Cyclopedia no qual Marx não apenas ressaltou sua oposição à figura de Bolívar, como também a imagem negativa que fazia dos habitantes da América hispânica. Seu juízo era implacável:

"como a maioria de seus compatriotas [Bolívar] era incapaz de todo esforço de longo prazo e sua ditadura degenerou rapidamente em uma anarquia militar na qual os assuntos mais importantes ficavam nas mãos de favoritos que arruinavam as finanças públicas e logo recorriam a meios odiosos para reorganizá-las" (MECW, v. 18, p. 221-222).

Tão implacável era esse juízo que o editor Charles Dana objetou a Marx que ao contrário dos demais artigos da Cyclopedia, esse estava escrito em um "estilo partidário" e solicitou que deixasse claro quais eram suas fontes. Mas o autor do verbete deu pouca atenção a seu editor. Em carta a Engels, datada de 14 de fevereiro de 1858, Marx admitiu que seu estilo era mesmo partidário e carregou ainda mais nos adjetivos referindo-se a Bolívar como "o mais covarde, miserável e ignóbil dos canalhas” (MECW, v. 40, p. 266). A aversão a Bolívar é ainda mais surpreendente na medida em que ele, em mais de uma ocasião e com diferentes argumentos havia defendido assim como Lincoln o fim da escravidão.

É verdade que a visada eurocêntrica não explica totalmente essa aversão. O risco de os novos governos na América Latina assumirem formas bonapartistas preocupava Marx. Mas também nessa justa preocupação sua visada reaparecia, uma vez que a oposição ao

2 Nela era ressaltada "a modéstia desse homem grande e bom que o mundo descobriu como herói quando já tinha caído como mártir” (MECW, v. 20, p. 99-100). 
regime de Luís Bonaparte, considerado como um obstáculo para o desenvolvimento da revolução europeia era deslocada, de modo às vezes mecânico, para sua análise de Simon Bolívar (ver o argumento de ZEA, 1983, p. 64).

Essa visada eurocêntrica se fez presente novamente na atitude de Marx e de Engels durante a guerra entre Estados Unidos e México. Ambos os autores tomaram partido decididamente pelo primeiro e Engels a esse propósito foi ainda mais efusivo do que seu companheiro. Já em 1847 escrevia ter "testemunhado a conquista do México e se regozijado com isso". Evidenciava desse modo aquela filosofia da história à qual fizemos referência e erigia o progresso como medida da história e o identificava com o movimento de emancipação dos trabalhadores. Nessa perspectiva, esse autor escrevia ainda referindo-se ao México: "Quando um país que até então vivia encerrado exclusivamente em si próprio, perpetuamente dilacerado por guerras civis e completamente impossibilitado de desenvolver-se (...) quando tal país é arrastado forçosamente pelo processo histórico, trata-se de um progresso" (MECW, v. 6, p. 527).

Dois anos depois, o mesmo Engels voltaria à carga e ridicularizaria aqueles que lamentavam "que a esplêndida Califórnia tenha sido tomada dos preguiçosos mexicanos, os quais nada fariam com ela". E depois de narrar a expansão das forças produtivas e do comércio que pela primeira vez teriam aberto o Oceano Pacífico à civilização, concluía:

"A 'independência' de uns poucos espanhóis californianos e texanos pode sofrer por causa disso e em alguns casos 'justiça' e outros princípios morais deverão ser violados; mas onde está o problema comparativamente a tais fatos de significação histórica mundial?" (MECW, v. 8, p. 365-366).

Analisando os escritos de Marx e Engels sobre a guerra dos Estados Unidos contra o México, Monjarás-Ruiz (1983, p. 108) apontou que o juízo mais acertado de ambos os autores a esse respeito foi a previsão de que a derrota deste último provocaria a subordinação do restante da América Latina à dominação estadunidense. Um olhar treinado pelas tragédias dos séculos XX e XXI, não deixa, assim, de se surpreender com o caráter positivo que atribuíam a essa dominação. 
A dificuldade para compreender a América Latina era análoga àquela que Marx enfrentou para compreender a dominação colonial na Índia. No artigo “The British Rule in India”, publicado em 10 de junho de 1853 no New York Daily Tribune, Marx atribuiu um caráter claramente positivo aos resultados da dominação britânica no subcontinente asiático. Muito embora ele lamentasse os efeitos destrutivos dessa dominação, afirmava que esta havia destruído as "semibárbaras e semicivilizadas comunidades" que caracterizavam a vida social na Índia e promovido, desse modo, uma verdadeira revolução social (MECW, v. 12, p. 131-132). Assim, apesar de toda dor que essa dominação pudesse provocar e "quaisquer que sejam os crimes da Inglaterra, ela era uma ferramenta inconsciente da história para realizar aquela revolução" (idem, p. 132). ${ }^{3}$

Marx, entretanto, começou a mudar sua visada a partir da luta pela independência da Irlanda, a qual permitiu que uma atitude crítica do processo de expansão econômica e política do capitalismo ocupasse gradativamente lugar em sua obra.. A dominação inglesa havia promovido uma destruição da agricultura e da incipiente indústria irlandesa que em muito se assemelhava àquela ocorrida na Índia. Essa destruição não havia dado lugar, assim como na Índia, a novas e modernas formas de organização da economia. Mas a atitude de Marx para com o movimento nacional irlandês era muito diferente daquela que havia tido com relação ao subcontinente indiano.

Para Marx, a Inglaterra era "o baluarte da grande propriedade territorial e do capitalismo europeu”, mas era na atrasada Irlanda que esse baluarte poderia sofrer uma derrota decisiva porque "a luta econômica se concentra exclusivamente sobre a propriedade territorial, porque esta luta é ali ao mesmo tempo uma luta nacional, e porque o povo se manifesta mais revolucionário e mais furioso do que na Inglaterra" (MECW, v. 20, p. 119). Não era no concentrado e organizado proletariado fabril das cidades industriais inglesas que Marx depositava as esperanças da revolução e sim nas atrasadas massas urbanas e rurais da Irlanda. Sua conclusão era surpreendente:

3 Essa chocante opinião a respeito da dominação colonial britânica foi novamente sustentada no artigo "The Future Results of Brithis Rule in India”, de 22 de julho de 1853. 
"No momento em que cesse a forçada União entre os dois países começará na Irlanda, ainda que sob formas antiquadas, uma revolução social" (idem, p. 119-120. Grifos meus).

Muito embora a revolução social na Irlanda pudesse ocorrer de modo diferente daquele esperado nos países nos quais o proletariado industrial encontrava-se concentrado e organizado, ou seja, muito embora a revolução social irlandesa pudesse assumir "formas antiquadas" e mesmo uma feição nacional Marx não apenas a apoiava como depositava nela a sua esperança, na medida em que a conectava com a revolução europeia. ${ }^{4}$

Essa nova atitude, a qual se distanciava claramente de uma filosofia da história, expressou-se de modo ainda mais nítido na apreciação que Marx passou a fazer do desenvolvimento do capitalismo na Rússia. O tema o atraiu enormemente a partir de 1873 e para estudá-lo melhor dedicou-se à aprendizagem do idioma russo. O estudo dessa questão e sua interlocução com intelectuais desse país afastaram Marx gradativamente daquela filosofia da história que se deixava entrever em escritos anteriores. Essa nova perspectiva pode ser percebida em sua carta de 1877 aos editores da Otiechesviennie Zpiski. Na missiva Marx sumariava as idéias de Nikolay Gavrilovich Chernyshevsky, segundo Marx "um grande estudioso e crítico russo", para o qual a Rússia ao invés de destruir a comuna rural para promover o desenvolvimento, poderia adquirir todos os seus frutos "sem sofrer seus tormentos, desenvolvendo suas próprias condições históricas". "Eu partilho seu ponto de vista sobre esta questão", afirmou Marx. E a seguir rejeitou toda tentativa de transformar sua análise do capital em uma filosofia na qual o curso da história universal fosse previamente traçado: "O capítulo sobre a acumulação primitiva não pretende mais do que traçar o caminho pelo qual na Europa ocidental a ordem econômica capitalista emergiu das entranhas da ordem econômica feudal." (MECW, v. 24, p. 199. Grifos meus.)

4 As minutas da reunião do Conselho Geral da Associação Internacional dos Trabalhadores de 14 de dezembro de 1869 registram: "Ele [Marx] considerou a solução da questão irlandesa como a solução da inglesa e a inglesa como a solução da europeia.” (MECW, v. 21, p. 413.) 
Essa passagem de Marx, a qual enfatiza que sua análise se restringia à Europa ocidental, é relevante para compreender a nova visada assumida. De fato, ela lembra uma importante alteração feita alguns anos antes na edição francesa do texto de 0 Capital. ${ }^{5}$ No capítulo sobre a acumulação primitiva, sobre o qual estava fundamentada toda a polêmica com os "marxistas" russos que se apropriavam do texto ao pé da letra, Marx decidiu alterar o texto da edição original alemã para enfatizar justamente o caráter historicamente circunscrito à Europa ocidental de sua análise. A comparação entre os textos evidencia a intenção de Marx:

\footnotetext{
"Na história da acumulação primitiva

"Na história da acumulação primitiva fazem época fazem época todas as revoluções todas as revoluções que servem como alavanca ao que servem como ponto de apoio avanço da classe capitalista em vias de formação e, à nascente classe dos capitalistas e principalmente, todas as que despojam as grandes principalmente todos os momentos massas de seus meios de produção e subsistência nos quais as grandes massas de tradicionais, lançando-as imprevistamente no homens são despojadas repentina mercado de trabalho. Mas a base de toda essa e violentamente de seus meios de evolução é a expropriação dos cultivadores. Ela subsistência para serem lançadas não se completou de uma maneira radical senão na no mercado de trabalho livre como Inglaterra, país, que terá, então, um papel principal proletários livres (vogelfreie). A em nosso esboço. Mas todos os países da Europa expropriação que priva o produtor ocidental percorrem o mesmo movimento, ainda que rural, o camponês, de sua terra serve segundo o contexto ele mude sua cor local, ou se restrinja de base a todo esse processo. Sua a um círculo mais estreito, ou apresente um caráter história apresenta uma modalidade menos fortemente pronunciado, ou segundo uma ordem diversa em cada país e em cada um de sucessão diferente [Elle ne s'est encore accomplie deles recorre as diferentes fases em d'une manière radicale qu'en Angleterre: ce pays diferentes ordens e em diferentes jouera donc nécessairement le premier rôle dans épocas históricas. Apenas na notre esquisse. Mais tous les autres pays de l'Europe Inglaterra, que aqui tomamos como occidentale parcourent le même mouvement, bien exemplo, ela reveste sua forma que selon le milieu il change de couleur locale, ou clássica [Nur in England, das wir se resserre dans un cercle plus étroit, ou présente daher als Beispiel nehmen, besitzt sie un caractère moins fortement prononcé, ou suive klassische Form]." (Marx, 1990, v. 1, un ordre de succession different] (Marx, 1872, v. 1, p. 876 ; MEW v. 23, p. 744 .) p. 315. Grifos meus)
}

O sentido dessa alteração torna-se ainda mais evidente no uso que Marx fez da edição francesa em sua troca de correspondência com Vera Zasulich em 1881, a respeito do destino da comuna rural russa. Nessa missiva, depois de citar a passagem de 0 Capital acima destacada, a qual afirmava que todos os países da Europa ocidental deveriam seguir o mesmo caminho de separação do produtor dos

5 Enrique Dussel (1990, p. 255-256) chamou a atenção para essa mudança e para sua importância. 
meios de produção e da consequente expropriação dos produtores agrícolas seu autor insistiu: "Portanto, a 'inevitabilidade histórica' desse processo está estritamente limitada aos países da Europa ocidental" (MECW, v. 24, p. 370).

A particularidade histórica russa era, assim, ressaltada, ao mesmo tempo em que era apontada uma via não-clássica (não-Ocidental) de modernização da sociedade russa. O caráter historicamente particular do desenvolvimento capitalista na Rússia fazia com que, para o autor de 0 capital, a comuna rural fosse nesse país "o ponto fulcral da regeneração social” (idem, p. 371). No primeiro rascunho a essa carta, Marx havia sido ainda mais enfático, escrevendo:

"Se a revolução vier no momento oportuno, se ela concentrar todas suas forças para permitir à comuna rural seu pleno desenvolvimento, esta poderá prontamente se desenvolver como um elemento de regeneração na sociedade russa e um elemento de superioridade sobre os países escravizados pelo sistema capitalista.” (idem, p. 360.)

A reflexão marxiana sobre o desenvolvimento do capitalismo na Rússia parece ter alterado até mesmo seu juízo sobre o domínio colonial na Índia. Referindo-se justamente àquelas comunidades que uma vez havia descrito como "semibárbaras e semicivilizadas" e cuja destruição havia considerado um fator de progresso histórico, Marx escreveu:

"No que diz respeito à Índia oriental, por exemplo, todos com a exceção de sir Henry Maine e gente de sua laia, sabem que a supressão da propriedade comunal foi apenas um ato de vandalismo inglês que conduziu os povos nativos não para a frente e sim para trás." (idem, p. 365).

Essa nova perspectiva que Marx formulou a partir de sua reflexão primeiro sobre a Irlanda e depois sobre o desenvolvimento do capitalismo na Rússia representa uma ruptura decisiva com toda filosofia da história e assentou as bases para uma melhor compreensão da realidade latino-americana. ${ }^{6}$ Mas trata-se apenas

6 Enrique Dussel (1990) destacou com ênfase a importância desse "último Marx" para a América Latina. 
de pistas e não de uma resposta acabada a nossas indagações. Para os que vivem neste continente esse deslocamento de perspectiva é fundamental e deveria servir como um ponto de partida para apreendermos nosso desenvolvimento desigual e combinado. Pois do que se trata, para aqueles marxistas que não querem fazer uma filosofia da história, é justamente, de interpretar a particularidade do desenvolvimento capitalista na América Latina. Esse nunca foi um problema para os partidos comunistas de nosso continente, os quais procuraram justificar a política da Internacional Comunista para as colônias e semicolônias por meio de uma teoria que não era, senão, "calco y cópia". 7

Para aqueles que se colocavam em outra perspectiva histórica e política, interpretar a América Latina a partir da obra de Marx implicava um esforço criativo de estudo de sua obra, de construção teórica e de um reconhecimento, ao menos implícito, de que a fidelidade à sua dialética implicava, às vezes, no afastamento de seu texto. De fato, também muitas das ideias de Marx estavam fora de lugar em nosso continente. Apropriadas de modo dogmático não faziam senão erguer barreiras cognitivas à compreensão de nossa história. Interpretar essa história foi, assim, o primeiro desafio dos marxistas latino-americanos, dentre eles os brasileiros. Daí que a investigação sobre nossa formação, ou seja, sobre a construção histórica de nossa particularidade, tenha atraído algumas das melhores inteligências como Caio Prado Junior, com seu Formação do Brasil Contemporâneo, de 1942, Nelson Werneck Sodré, com Formação da Sociedade Brasileira, de 1944, e Formação Histórica do Brasil, de 1962, e Antonio Cândido, com a Formação da Literatura Brasileira, de 1957, ou ainda, fora do espectro do marxismo, mas em profundo diálogo com ele, Celso Furtado, com Formação econômica do Brasil, de 1959.

7 Construída após a afirmação de um programa, a sofrível interpretação da América Latina pelos partidos comunistas, elaborada a partir da década de 1920 , não fazia senão reproduzir uma cultura de manuais na qual as diversas etapas do desenvolvimento econômico e social pelas quais a Europa supostamente teria passado eram universalizadas. Essa operação intelectual visava sustentar as políticas de alianças com a burguesia nacional e a afirmação de programas "nacional-populares", "democrático-populares" ou "democrático-nacionais". 


\section{Marxismo e teoria da dependência}

A necessidade de desenvolver uma interpretação de nossa realidade torna a trajetória do marxismo latino-americano desviante. Perry Anderson (2004) analisou o deslocamento que ocorreu no marxismo europeu do pós-guerra para os temas da filosofia e da crítica literária. A necessidade de o marxismo interpretar a América Latina e, particularmente, o Brasil impediu que a pesquisa histórica, social, política e econômica sofressem o mesmo deslocamento. Pode-se, até mesmo, dizer que a filosofia e a crítica literária brasileiras foram desde cedo marcadas pela análise histórica e social, inclusive no marxismo, ou seja, que o objetivo explícito dessa filosofia e dessa crítica literária foi, senão sempre pelo menos na maioria das vezes, interpretar o Brasil.

Isso é evidente naqueles autores já citados que assumiram como desafio o estudo da formação do Brasil. Mas pretendo apresentar de modo mais detalhado um caso que tinha tudo para ser a realização do "marxismo ocidental" no Brasil, mas que nunca o foi: o lendário "Seminário d'O Capital", aquele grupo de estudos sobre a obra de Marx integrado por José Arthur Giannotti, Fernando Henrique e Ruth Cardoso, Paul Singer, Fernando Novais, Octávio Ianni e outros.

De certo modo, a conformação do Seminário tinha um caráter de contestação à figura de Florestan Fernandes e àquilo que Gabriel Cohn chamou de seu "ecletismo bem temperado". ${ }^{8}$ Mas embora esse desafio existisse, as exigências de rigor e cientificidade que Fernandes havia imposto ao seu próprio trabalho eram por todos partilhadas, daí que Giannotti pudesse retrospectivamente ressaltar "a vocação científica do grupo" (1999, p. 116) e Roberto Schwarz dizer que o objetivo do grupo era "uma concepção científica superior" (1999, p. 89).

Aqui está um ponto importante que merece ser destacado. A crítica explicita à tradução das idéias marxistas realizadas no Brasil

8 Ver a opinião de Sallum Jr. (2002, p. 75-76). O projeto intelectual de Florestan procurava integrar de modo interdependente e complementar os diferentes aportes da sociologia sistemática, de Weber; da sociologia diferencial, de Marx; da sociologia comparada, de Durkheim; da sociologia descritiva, da Escola de Chicago; e da sociologia teórica, de Mannheim. Assim, a formação do grupo, ao afirmar as idéias de Marx como um ponto de partida, claramente desafiava Florestan. 
pelo stalinismo, que sempre atravessou o grupo, encontrava-se amparada em uma também explícita distinção ente ciência e ideologia. Distinção essa que deveria ser viabilizada metodologicamente por uma leitura rigorosa d'O Capital. O papel de Giannotti como guardião epistêmico era, aí, crucial e foi por meio dele que o enfoque estruturalista de Martial Guéroult e Victor Goldschmidt se tornou um modelo para uma leitura rigorosamente interna do texto de Marx, permitindo o que consideravam ser uma abordagem científica desta. Paulo Arantes e Roberto Schwarz (1999, p. 91) já destacaram a ironia presente no fato de que a empresa intelectual de um grupo que pretendia renovar criticamente e mesmo revolucionar a recepção de Marx no Brasil estava sustentada em uma técnica de leitura que era lugar comum para qualquer estudante do secundário francês.

Ironias à parte, a separação entre ciência e ideologia preconizada pelo grupo não deixava, entretanto, de ser ela mesma ideológica. A política permanecia não apenas como um objeto, mas também como um desejo. Todos liam 0 Capital, confessou Giannotti, com o objetivo de "entender o estágio em que se encontravam as relações sociais do desenvolvimento econômico e social brasileiro, com o intuito muito preciso de poder avaliar as políticas em curso" (Giannotti, 1998, p. 116). E a "aposta no rigor e na superioridade intelectual de Marx (...) era redefinida nos termos da agenda local, de superação do atraso por meio da industrialização" (Schwarz, 1999, p. 88), o que impedia os membros do Seminário de se afastarem das diretrizes do Partido Comunista Brasileiro (PCB) ou da Comissão Econômica para a América Latina (Cepal) tanto quanto afirmavam querer.

O "estudo rigoroso" da obra de Marx tinha, assim, um claro propósito instrumental. $\mathrm{O}$ contexto é importante para compreender esse propósito. A promessa de desenvolvimento e a ideologia do progresso contida no programa de Juscelino Kubitschek pareciam materializar-se no vertiginoso crescimento industrial e na construção de Brasília. Nesse cenário, no qual o Brasil moderno parecia travar sua luta definitiva contra o Brasil arcaico o que interessava a esses autores era "afinar conceitos científicos que lhes fornecessem instrumentos de intervenção na própria universidade e na política brasileira." (GIANNOTTI, 1998, p. 119.) 
Dentre aquelas questões de ordem teórica e interpretativa que se manifestavam com mais urgência, estava o acerto de contas com a idéia de burguesia nacional corrente tanto no discurso nacional-desenvolvimentista como naquele que tinha sede no PCB. ${ }^{9}$ Foi numa clara contraposição a essa idéia que apareceu a obra Empresário industrial e desenvolvimento econômico, de Fernando Henrique Cardoso (1964), na qual eram eram apresentadas as inconsistências do projeto de hegemonia política da burguesia industrial brasileira. Presa entre motivações e interesses tradicionais que a prendiam ao latifúndio e ao capitalismo internacional, ao qual se encontrava associada, essa burguesia encontrava-se impossibilitada de aliar-se de modo duradouro às classes urbanas e populares.

Cardoso concluía seu livro com uma disjuntiva dilacerante. Ou esse capitalismo associado se consolidaria assegurando à burguesia brasileira a condição de sócia-menor do capitalismo ocidental ou as massas urbanas e os grupos populares manifestariam uma nova forma de organização capaz de "levar mais adiante a modernização política e o processo de desenvolvimento econômico do país.” Em última instância, concluía Cardoso, "a pergunta será então, subcapitalismo ou socialismo?" (CARDOSO, 1964, p. 187.)

Talvez, dado o ceticismo e a desconfiança que Cardoso demonstrou desde cedo perante o movimento operário, a interrogação já contivesse sua resposta. Mas outras são as questões que gostaria de levantar neste momento. Os méritos e os limites desse livro podem ser encontrados na relação que estabelece entre a teoria marxista e

9 O Partido Comunista Brasileiro reagiu às transformações que se tornavam evidentes na sociedade brasileira deixando para trás sua fase esquerdista, destacando, na conhecida Declaração de Março de 1958, a existência de uma contradição fundamental entre uma burguesia "nacional e progressista" e o imperialismo norte-americano e seus aliados. Anunciada a contradição, a política indicada foi a constituição de uma Frente Nacionalista, constituída pelos "patriotas da burguesia nacional", a pequena burguesia e o proletariado urbano e rural. Tal frente poderia desenvolver suas forças pacificamente, chegando até mesmo a constituir, por esses meios, um governo nacional e a realizar "por formas e meios pacíficos”, a revolução antiimperialista e antifeudal (PCB, 1982). As diretrizes anunciadas pela Declaração de Março foram ratificadas pelo $5^{\circ}$ Congresso do PCB, realizado em 1960. O apoio à candidatura do marechal Lott, em 1961 e o suporte dado pelo partido ao governo de João Goulart foram os desdobramentos práticos dessas teses. 
a pesquisa empírica. A apropriação do marxismo por parte de Cardoso não era feita de modo mecânico. O objetivo do autor era uma análise das características particulares que a burguesia assumia em uma sociedade que era desviante, mas não alheia ao desenvolvimento do capitalismo. O marxismo deveria, desse modo, viabilizar uma interpretação do Brasil que evitasse considerar seu "caso" como um "evento singular discreto" à maneira de um historicismo vulgar, ao mesmo tempo em que rejeitasse as tentações do economicismo que apresentava a formação da ordem capitalista industrial em nosso país como uma "tendência inexorável" (CARDOSO, 1964, p. 42-43).

Reconhecer o mérito dessa abordagem não implica, entretanto, afirmar sua exclusividade, ou mesmo sua originalidade. As críticas à noção de "burguesia nacional" e aos esquemas etapistas que caracterizavam a análise do PCB eram voz corrente na esquerda anti-stalinista da época e, particularmente, na Organização Revolucionária Marxista-Política Operária (Polop), fundada em 1961 (cf. Sader, 1997, p. 110 e Mattos, 2002, p. 186). E haviam sido antecedidas em muito pelas pioneiras análises da Liga Comunista Internacionalista na década de 1930 e, particularmente pelo "Esboço de uma análise da situação econômica e social do Brasil", de Mario Pedrosa e Lívio Xavier (1987).

Crítica similar poderia ser encontrada em outros países e antecedendo muito os trabalhos do "Seminário d'O Capital". Na Argentina, Nahuel Moreno havia formulado em 1948 "Cuatro tesis sobre la colonización española y portuguesa en América” (Moreno, 1957) e o agudo historiador argentino Milcíades Peña, um personagem sobre o qual o marxismo latino-americano deveria prestar mais atenção, escreveu entre 1955 e 1957 um conjunto de importantes textos daquilo que pretendia ser um amplo painel da formação e da perspectiva das classes sociais na Argentina (ver PEÑA, 1975, 1975a, 1975b, 1975c, 1975d e 1975e). ${ }^{10}$

10 Em sua curta vida, Milcíades Peña (1933-1965) produziu uma obra extremamente significativa na qual empreendeu um importante esforço de revisão da história argentina. No mesmo ano em que Cardoso publicou seu livro sobre os empresários industriais, Peña deu início à publicação de três artigos na revista Fichas de Investigación Económica y Social, reunidos logo depois no livro Industria, burguesía industrial y liberación nacional (1974). 
Os limites da abordagem de Fernando Henrique Cardoso ficariam mais evidentes posteriormente com a publicação em co-autoria com Enzo Faletto de sua magnum opus Dependência e Desenvolvimento na América Latina (Cardoso e Faletto, 2004). Criticando o dualismo estrutural que caracterizava muito das teorias do subdesenvolvimento, Cardoso e Faletto propunham uma "análise integrada do desenvolvimento", na qual este era concebido como "o resultado da interação de grupos e classes sociais que têm um modo de relação que lhes é próprio" (2004, p. 34). O foco da análise passava, assim, a ser "o estudo das estruturas de dominação e das formas de estratificação social que condicionam os mecanismos e os tipos de controle e decisão do sistema econômico em cada situação particular.” (idem, p. 37.)

O pressuposto era o mesmo que animava Empresário industrial e desenvolvimento econômico, construir uma análise que permitisse a interpretação de casos particulares, rejeitando tanto o recurso a teorias ad hoc como a generalizações abstratas. Mas os objetivos de Dependência e Desenvolvimento na América Latina eram muito mais ambiciosos, uma vez que essa obra deixava de lado os estreitos quadros da sociedade brasileira e adotava para a análise do desenvolvimento uma perspectiva latino-americana. Para tal, seus autores procuravam por meio da noção de dependência aludir às condições particulares de existência e funcionamento do sistema econômico e do sistema político bem como as relações que estes mantinham nos planos interno e externo, insistindo "na natureza política dos processos de transformação econômica.” (idem. p. 179.) ${ }^{11}$

De modo apropriado, João Quartim de Moraes perguntou à época a respeito do "estatuto teórico da teoria da dependência" e, mais precisamente, a respeito da relação desta com a teoria marxista (Moraes, 1972). Respondendo a Weffort (1989), que dogmaticamente procurava contrapor uma teoria baseada na idéia de nação a uma teoria baseada na idéia de classe, Cardoso explicou que não havia procurado construir uma "teoria da dependência" e sim fazer uma "análise con-

11 Assim, "Ao considerar a 'situação de dependência', na análise do desenvolvimento latino-americano, o que se pretende ressaltar é que o modo de integração das economias nacionais no mercado internacional supõe formas distintas de inter-relação dos grupos sociais de cada país, entre si e com os grupos externos." (CARDOSO \& FALETTO, 2004, p. 43.) 
creta das situações de dependência". O conceito de dependência seria constituído por meio da saturação histórica das contradições particulares que lhe dariam sentido. Mas esse conceito não estaria definido no campo teórico do modo de produção. Tratar-se-ia de um conceito "reflexo" que seria "explicado por conceitos que constituem a teoria do capitalismo na fase imperialista (...). Quando, entretanto, o conceito de dependência se refere às formações sociais (...) o procedimento adequado para construi-lo teoricamente é o de reter conceitualmente as contradições que ele quer expressar." (CARDOSO, 1972, p. 129.)

Afirmando que não pretendia construir uma teoria geral da dependência, mas apenas aplicar o conceito às formações sociais, Cardoso se eximia, desse modo, de explicar o conceito de dependência por meio das categorias que constituem a teoria do capitalismo e procurava resolver as dificuldades conceituais postas por uma teoria da dependência por meio do estudo empírico das realidades nacionais concretas. A dificuldade de pensar a América Latina por meio das categorias d'O Capital era contornada por Fernando Henrique Cardoso, mas não solucionada. Por essa razão Marx não era citado em todo o texto e as categorias marxianas da análise do capitalismo não apareciam em sua análise da dependência. Embora não fosse citado, Marx comparecia em Dependência e Desenvolvimento na América Latina, como de resto no conjunto da produção da década de 1960 dos membros do "Seminário d'0 Capital". Mas o fazia na condição de epistemólogo e era como tal que ele estava sempre presente nessa produção.

Em Dependência e Desenvolvimento na América Latina está consolidada uma notável análise da situação latino-americana que procurava articular as dimensões política e econômica. Mas as questões fundamentais de todo processo de dependência, a produção de valor e mais-valor e a transferência de mais-valor, não eram abordadas. Era justamente o tratamento teórico destas questões o que permitiria esclarecer os processos concretos que teriam lugar nas diferentes realidades nacionais e, principalmente, as formas que a contradição entre as classes assumiria em cada país.

Em sua reconstrução da trajetória do "Seminário d'O Capital", Roberto Schwarz (1999, p. 103) apontou que o grupo não se interessou pela crítica de Marx ao fetichismo da mercadoria. Mas é sempre conveniente recordar que a análise marxiana do fetichismo 
é um capítulo de sua teoria do valor. É justamente esta a que parece estar ausente. As dificuldades que José Serra e Fernando Henrique Cardoso (1979) encontraram para responder às objeções de Ruy Mauro Marini e o tratamento pobre que deram às categorias de valor e de mais-valor nessa ocasião tornam ainda mais sentida essa ausência (cf. MARINI, 2000, p. 177-181).

Na conclusão de Dependência e Desenvolvimento na América Latina esses limites revelam-se de modo dramático. Nela a oposição entre "socialismo e subcapitalismo" era substituída de modo ainda não desenvolvido teoricamente pela oposição entre dependência e interdependência. A nova situação da dependência, caracterizada pela inserção dos "interesses externos" no setor de produção para o mercado interno e por sua sustentação em alianças políticas das quais fariam parte as classes urbanas, tornaria possível que os países dependentes superassem a situação de subdesenvolvimento por meio de um desenvolvimento capitalista associado.

A base dessa nova interdependência estaria na crescente solidariedade entre os investimentos industriais estrangeiros e a expansão econômica do mercado interno que se evidenciaria em uma forte tendência ao reinvestimento de parte dos lucros obtidos pelas empresas transnacionais no mercado interno (cf. CARDOSO \& FALETTO, 2004, p. 164). Assim, mesmo que o novo tipo de desenvolvimento implicasse em mecanismos de controle da economia nacional que fugissem do controle interno, excluindo qualquer alternativa, devido à unificação dos sistemas produtivos e dos mercados (idem, p. 167), isto não implicaria uma intensificação da dependência: "vínculos posteriores com a economia internacional poderiam ser do tipo normal nas economias modernas, nas quais sempre há interdependência” (idem, p. 165).

O que esses autores consideravam como vínculos de "tipo normal com a economia internacional" era um comércio internacional que não implicasse em uma transferência de valor, ou seja, um comércio mundial ricardiano, no qual as vantagens comparativas de cada nação garantiriam mútuos benefícios. ${ }^{12}$ Em termos teóricos

12 Anwar Shaikh (1991, cap. 4) argumentou vigorosamente que a lei ricardiana dos custos comparativos não é compatível com a teoria marxiana do valor: 
esse argumento foi colocado de modo mais intenso e acabado na polêmica que José Serra e Fernando Henrique Cardoso moveram contra Ruy Mauro Marini. Em uma passagem crucial de seu texto Cardoso e Serra questionaram a possibilidade de transferência de valor por meio do comércio internacional afirmando que "não havendo mobilidade da força de trabalho fica difícil estabelecer-se, em escala internacional, o conceito de tempo de trabalho socialmente necessário, o qual, por sua vez, é crucial como requisito para a operação da lei do valor.” (1979, p. 49.)

Marini surpreendeu-se com esse argumento e não viu o nexo anunciado por Serra e Cardoso entre a mobilidade da força de trabalho e o tempo de trabalho socialmente necessário. E de fato, tal nexo não existe na obra de Marx. Mas tal nexo é importante para a teoria ricardiana do comércio. Daí que, sem maiores explicações, Serra e Cardoso simplesmente rejeitassem a operação da lei do valor no comércio mundial. Como consequiência ao invés de discutir as diferenças de "produtividade e de valores unitários" mostraram-se interessados na variação dos preços relativos e na deterioração dos "índices de relações de troca" que teriam como "componente dinâmico na explicação" a "luta de classes" (SERRA \& CARDOSO, 1979, p. 45).

A referência à "luta de classes" tinha o propósito de demarcar posições entre uma leitura aberta, heterodoxa e até mesmo radical e outra economicista e ortodoxa. No argumento de Raúl Prebisch aceito por Serra-Cardoso, os aumentos de produtividade na produção de máquinas e equipamentos nos países desenvolvidos seriam rápidos e não se traduziriam em redução proporcional do preço unitário, enquanto que nos países subdesenvolvidos os aumentos de produtividade seriam lentos e se refletiriam em reduções proporcionais do preço. As razões para tal adviriam do fato de que nos países industrializados os ganhos de produtividade seriam repartidos entre capitalistas e trabalhadores, enquanto que nos países periféricos isso não ocorreria devido, entre outras razões, à incapacidade política dos trabalhadores imporem níveis salariais mais elevados e à debilidade das burguesias nacionais. As diferenças salariais decorrentes da luta de classes seriam, assim, cruciais para explicar o comportamento desigual dos preços dos produtos 
comercializados por nações industrializadas e periféricas (cf. SERRA \& CARDOSO, 1979, p. 43). Daí a conclusão:

Sem que se considere, por um lado, a capacidade de luta dos trabalhadores industriais no Centro bem como a defesa pelos empresários de seus interesses monopolistas e, por outro, a fraqueza relativa de ambos na periferia, não se explica o intercâmbio desigual, processo que reflete as condições reais das relações sociais nas quais se desenvolve a produção capitalista. (idem, p. 45.)

Este argumento que parece à primeira vista fazer sentido quando mobilizado para explicar as relações centro-periferia demonstra sua fragilidade quando utilizado para explicar as diferenças existentes entre países industrializados, como por exemplo, a Inglaterra e os Estados Unidos na primeira metade do século XX. Afinal, de que lado do Atlântico era possível encontrar uma classe operária mais organizada e uma luta de classes mais intensa? Certamente não era do lado dos Estados Unidos, para onde, paradoxalmente, a balança do comércio exterior inclinava-se favoravelmente. $\mathrm{O}$ recurso à luta de classes para solucionar os impasses aos quais chega o modelo explicativo tem o valor de um argumento ad hoc.

Por sua vez, um argumento que estivesse assentado nas categorias marxianas poderia debruçar-se sobre os processos de transferência de valor por meio do mercado mundial e, desse modo, chegar a resultados mais consistentes a respeito da dependência. A superioridade teórica do argumento de Ruy Mauro Marini em sua Dialética da dependência (2000) reside justamente neste ponto. Considerado a partir dessas categorias, o problema da dependência encontra sua explicação a partir de uma perspectiva totalizante que articula os processos de produção de mercadorias em contextos nacionais de desenvolvimentos desiguais e combinados com a circulação de mercadorias no mercado mundial e a transferência de mais-valor que esta possibilita. Este tema foi apenas esboçado por Marx, mas esse esboço já fornece importantes pistas para a solução.

Analisando as diferenças nacionais de produtividade de trabalho, Marx apontou, no livro I de 0 capital, que a intensidade média do trabalho varia de país para país. Comparando um trabalho mais intensivo com outro menos intensivo se verificará que o trabalho 
mais intensivo produz em um mesmo tempo mais valor. Desse modo, "o trabalho nacional mais produtivo é considerado ao mesmo tempo como mais intensivo, sempre que a nação mais produtiva não seja obrigada pela concorrência a reduzir o preço de venda de suas mercadorias até o limite de seu valor" (MARX, 1990, v. 1, p. 702).

Adquirem posição predominante no comércio internacional aquelas nações nas quais a intensidade e produtividade do trabalho superam o nível internacional. E muito embora o salário nominal - o equivalente da força de trabalho expresso em dinheiro - seja mais elevado nesses países do que nos demais, o preço relativo do salário, ou seja, sua relação com o mais-valor e com o valor do produto será nele mais baixo do que nos países nos quais predomine um regime capitalista menos desenvolvido. Um exemplo numérico pode ajudar a esclarecer essa questão. Ernest Mandel (1982, p. 250-254) propôs, em sua análise da troca desigual, um exemplo no qual dois países - A (desenvolvido) e B (subdesenvolvido) - importam e exportam mercadorias entre si. $O$ valor do pacote de mercadorias exportado por A corresponde a $5.000 c+4.000 v$ $+4.000 s=13.000$, onde $c$ corresponde ao capital constante, $v$ ao capital variável e $s$ o mais-valor, a taxa de lucro $(\mathrm{s} /[\mathrm{c}+\mathrm{v}])$ é igual a $44 \%$ e a taxa de mais-valor ( $\mathrm{s} / \mathrm{v}$ ) igual a $100 \%$. O valor do pacote de mercadorias exportado por B corresponde a $200 \mathrm{c}+2.000 \mathrm{v}+$ $1.800 \mathrm{~s}=4.000$, a taxa de lucro é igual a $82 \%$ e a taxa de mais-valor igual a $90 \%$. Perceba-se que nesse caso, embora a taxa de lucro de $\mathrm{B}$ seja quase o dobro de A, a taxa de mais-valor (taxa de exploração) de A é maior do que a taxa de mais-valor de B.

Nessa situação, que pressupõe diferentes taxas de lucro nacionais, a equivalência de valores internacionais em uma situação na qual B exporta 4.000 unidades monetárias é a seguinte: $1.538 c^{\mathrm{A}}+$ $1.231 v^{\mathrm{A}}+1.231 s^{\mathrm{A}}=200 c^{\mathrm{B}}+2.000 v^{\mathrm{B}}+1.800 s^{\mathrm{B}}$. Assim, embora valores internacionais sejam trocados por seus equivalentes esses valores iguais representam quantidades desiguais de trabalho decorrentes das diferenças de produtividade entre as diferentes nações: $1.231 v^{\mathrm{A}}<2.000 v^{\mathrm{B}}$. Mas ao contrário do que parecem insistir Cardoso e Serra - e antes deles Raúl Prebisch -, a questão fundamental nessa diferença não reside nos custos salariais desiguais e sim no fato de que a hora de trabalho de A é mais produtiva do que a hora 
de trabalho de B. A troca desigual é, assim, uma transferência de valor, ou seja, de quantidades de trabalho. ${ }^{13}$

Embora Mandel assuma como pressuposto que não existe um nivelamento internacional das taxas de lucro a troca desigual persistiria mesmo na hipótese de que ocorresse o nivelamento. Dividindo a massa total de mais-valor pela massa total de capital adiantado (5800/11200), obtém-se uma taxa de lucro do conjunto do sistema igual a aproximadamente $52 \%$. Equalizadas nesse índice as taxas de lucro tem-se que para $\mathrm{A}$ o preço de produção do pacote de mercadorias seria $5.000 c+4.000 v+4.661 p r=13.661$ e para $B$ esse preço seria de $200 \mathrm{c}+2.000 \mathrm{v}+1.139 \mathrm{pr}=3.339$. Nesse caso a troca se daria nos seguintes termos: $1.222 c^{\mathrm{A}}+978 v^{\mathrm{A}}+1.139 p r^{\mathrm{A}}=$ $200 c^{\mathrm{B}}+2.000 v^{\mathrm{B}}+1.139 p r^{\mathrm{B}}$, portanto, $978 v^{\mathrm{A}}<2.000 v^{\mathrm{B}}$, consistira em uma diferença ainda maior. A troca de quantidades desiguais de trabalho permaneceria, assim, como o fundamento da troca desigual. Marx descreveu rapidamente esse processo n'O Capital:

Os capitais investidos no comércio exterior podem levantar uma quota mais elevada de lucro, em primeiro lugar porque competem com mercadorias produzidas com facilidades de produção menos desenvolvidas, por isso o país mais adiantado vende suas mercadorias acima de seu valor, ainda que mais baratas do que os países competidores. (...) O país mais favorecido obtém uma quantidade maior de trabalho em troca de uma menor, ainda que a diferença, o excedente, seja embolsado por uma determinada classe, como ocorre em geral com o intercâmbio ente capital e trabalho (MARX, 1990, v. 3, p. 344-346.)

A concorrência tende, portanto, a agravar as condições nas quais ocorre o processo de distribuição do mais-valor na esfera mundial. Esse processo é completamente assimétrico e ditado não apenas pelos diferentes níveis nacionais de intensidade e produtividade do trabalho como também pelas condições econômicas e políticas que permitiriam a alguns países sustentar o preço de mercadorias

13 Esclareça-se que a competição entre setores industriais e no interior de setores industriais, ou seja, o intercâmbio desigual, não é a única fonte de transferência de valor. A estas fontes é possível acrescentar a repatriação de lucros, royalties e rendas, os empréstimos bancários e as dívidas públicas dos países periféricos (cf. p. ex. Shaikh, 1991 e Cooney, 2004). 
acima de seu valor, enquanto imporiam a outros preços inferiores ao valor. Nessas condições não há como falar de interdependência a não ser que esta signifique simplesmente subordinação.

Isso implica em uma abordagem economicista como Cardoso e Serra afirmaram? Seria uma abordagem economicista se as diferenças de produtividade fossem atribuídas exclusivamente ao variado desenvolvimento tecnológico. A abordagem marxiana é, entretanto, muito mais complexa. Segundo Marx a produtividade é "determinada por uma ampla gama de circunstâncias; é determinada dentre outras coisas pelo grau médio de habilidade dos trabalhadores, o nível do desenvolvimento da ciência e de suas aplicações tecnológicas, a organização social do processo de produção, a extensão e eficiência dos meios de produção e as condições encontradas em seu ambiente natural." (MARX, 1990, v. 2, p. 130.) É, pois, no desenvolvimento histórico desigual e combinado do capitalismo que encontraremos as determinações das diferentes produtividades do trabalho. A luta de classes atravessa essas múltiplas determinações, sobredeterminando-as.

O que a recorrente acusação de economicismo aventada por Cardoso e Serra revela, por outro lado, é uma concepção de atividade econômica na qual a luta de classes não tem lugar. Mas é, justamente, no processo de produção de mercadorias que a luta de classes ocorre de modo mais intenso. Na obra de Marx a luta de classes não ocorre depois de encerrada a jornada de trabalho; ela tem lugar no próprio processo de produção. As categorias de valor, mais-valor, lucro, taxa de mais-valor, taxa de lucro e produtividade do trabalho, às quais fizemos referência ao longo deste texto expressam relações sociais marcadas pelo conflito social. Daí que elas representem o antagonismo social ao invés das possibilidades de harmonização dos interesses como ocorre com as categorias ecléticas sobre as quais muitos dos argumentos de Cardoso e Serra repousavam.

\section{Grandezas e misérias de uma tradição crítica}

Dependência e Desenvolvimento na América Latina, juntamente com o restante da produção teórica do membros do "Seminário d'O Capital" Marx, constitui um ponto alto do pensamento marxista 
brasileiro ao mesmo tempo em que revela a dificuldade em articular as dimensões teórica e empírica da pesquisa marxista que se expressava nesse grupo, evidenciando seus limites. Contribuía para exacerbar essa dificuldade a divisão de trabalho que imperava nesse grupo. Uma divisão que, segundo um dos expoentes do Seminário "sempre foi prezada; mais ainda, cultuada, pois entendíamos que nossas práticas públicas e políticas somente poderiam se legitimar a partir dos particularismos de nossas respectivas tradições." (Giannotti 1998, p. 121.) Se o objetivo era legitimar carreiras intelectuais em um contexto de institucionalização crescente das ciências humanas tal divisão de trabalho sem dúvida deu bons frutos. Mas embora os beneficiados possam se regozijar com seu sucesso, essa estratégia teve um impacto negativo sobre o próprio desenvolvimento da teoria marxista.

Cabe ressaltar, entretanto, a dimensão da contribuição dos membros do "Seminário d'O Capital" para o desenvolvimento do pensamento marxista no Brasil. A importância capital dos estudos do Seminário, principalmente daqueles voltados para a compreensão do Brasil, reside no golpe fatal que assestaram nas teses do "feudalismo brasileiro" e da burguesia nacional. Essas teses, que durante decênios embasaram as políticas conciliadoras do marxismo oficial no Brasil foram completamente desacreditadas pelos estudos de Fernando Novais, Fernando Henrique Cardoso, Octávio Ianni e outros.

De vários modos, dentre os quais os políticos não são os menores, as gerações posteriores ao Seminário superaram-no. Mas coube aos autores a ele vinculados estabelecer uma medida a partir da qual os trabalhos posteriores podem ser comparados e evidenciar as dificuldades próprias à construção da unidade entre pesquisa marxista teórica e empírica. A tradição crítica que se fazia presente no "Seminário d'O Capital" (mas não se restringia apenas a ele) deixou um importante legado e assentou as bases para uma interpretação da realidade brasileira e latino-americana, mas não deixou de mostrar seus limites.

Essa corrente intelectual, entretanto, agonizou lentamente a partir dos anos 1970, à medida que seus expoentes ascenderam a posições de poder (cf. COGGIOLA, 2005). Os compromissos com a política cotidiana se fizeram cada vez mais intensos arrefecendo o impulso crítico que haviam sido exibidos anteriormente. Na década 
de 1990, já na presidência da República, Fernando Henrique Cardoso não era senão uma grosseira caricatura de si mesmo. Uma leitura retrospectiva poderá procurar nas ideias correntes daquele Seminário a miséria de nosso presente, mas o idealismo dessa leitura que procura as determinações da luta de classes nas ideias salta aos olhos.

Detive-me na exposição das grandezas e misérias que parecem caracterizar a produção científica dos membros desse Seminário por que creio que ela evidencia as dificuldades reais de afirmação de um marxismo latino-americano ou brasileiro capaz de unificar pesquisa teórica e pesquisa empírica. E optei por apresentar rapidamente a modalidade de manifestação dessa dificuldade na obra de Fernando Henrique Cardoso uma vez que ela é não apenas a mais conhecida, como, também, a que melhor expressou certo modo de interpretar o Brasil cujos fundamentos foram lançados no "Seminário d'O Capital". Foi por isso mesmo aquela que evidenciou de modo mais intenso em nosso país os dilemas do marxismo na América Latina.

Seria essa dificuldade uma refração da separação entre teoria e prática que caracterizaria o marxismo ocidental segundo a versão de Perry Anderson? Não o creio. É claro que na trajetória do Seminário alguns mais apressados poderiam encontrar a separação entre teoria e prática que se evidencia na Europa. De certo modo, a atividade do grupo prefigurou um deslocamento do marxismo para o interior das universidades que se tornou mais evidente depois do Ato Institucional 5, em 1968. Mas esse deslocamento pode esconder o fato de que para vários dos membros do Seminário a política era parte constitutiva de sua práxis e que a própria agenda de pesquisa era politicamente orientada. Fernando Henrique Cardoso não é o melhor exemplo dessa práxis, uma vez que a abraçou apenas tardiamente, muito embora seja o que tenha ido mais longe. Mas não podemos esquecer que Paul Singer, um dos fundadores da Polop, também fazia parte do grupo. ${ }^{14}$

14 Essa relação com a política que caracterizava tão intensamente o marxismo brasileiro, mesmo aquele sediado nas universidades, ficava ainda mais evidente na segunda geração do Seminário d'O Capital, da qual faziam parte Emir Sader, Francisco Weffort, João Quartim de Moraes, Paulo Sandroni e Ruy Fausto, dentre outros. Além do mais, a mesma dificuldade de articular pesquisa teórica e pesquisa empírica se manifestava no Rio de Janeiro, onde os vínculos com 
Em que reside, pois, essa dificuldade de articular de modo apropriado a pesquisa teórica e a pesquisa empírica de modo a permitir uma compreensão profunda da realidade latino-americana e da brasileira em particular? As vicissitudes históricas da difusão do marxismo em nosso subcontinente podem explicar os bloqueios políticos a essa compreensão. A hegemonia do stalinismo e do populismo, bem como as tendências antiintelectualistas que se faziam presentes nessas correntes foram sem dúvida importantes barreiras, as mais difíceis de transpor. Mas se quisermos superar esses obstáculos é preciso reconhecer as "cegueiras e obstáculos cognitivos" que se manifestavam no âmbito da própria teoria.

A realidade rebelde constituída pelo caráter desviante do capitalismo que tem lugar neste subcontinente colocou desafios teóricos e interpretativos para o pensamento crítico, o qual nem sempre soube enfrentar de modo apropriado. ${ }^{15}$ Foi no trabalho de formulação teórica que as maiores dificuldades se apresentaram. Detendo-se onde era preciso avançar muitos enfrentaram essas dificuldades subsumindo a realidade das formações econômicosociais de nosso continente a uma estreita lógica do capital que apagava as diferenças; tinham as soluções, mas lhes faltavam as perguntas. Outros avançaram por caminhos tortuosos, deixando de lado a teoria e empenhando-se em descrições densas de nossas realidades; foram capazes de identificar questões pertinentes, mas não tinham as respostas.

A solução do problema parece estar na construção de uma unidade profunda entre teoria e prática, pesquisa teórica e pesquisa empírica. O pressuposto, mais uma vez, o de um retorno a Marx e, particularmente a sua crítica da economia política. Enfrentar de modo crítico os desafios apresentados por sua obra, reconhecen-

a política e, particularmente com o Partido Comunista Brasileiro eram mais intensos e se expressavam por meio da revista Civilização Brasileira.

15 Segundo Marini: "Frente ao parâmetro do modo de produção capitalista puro, a economia latino-americana apresenta peculiaridades, que às vezes se dão como insuficiências, e outras - nem sempre distinguíveis facilmente das primeiras como deformações. (...) é por isso que mais que o capitalismo, o que temos é um capitalismo sui generis, que só ganha sentido se o contemplarmos tanto a nível nacional como, principalmente, a nível internacional.” (MARINI, 2000, p. 106.) 
do seus limites e lacunas é condição essencial. A identificação dos pontos cegos da teoria deve ter como consequência uma paciente prática teórica capaz de restaurar sua capacidade explicativa. A América Latina é, sem dúvida, um desses pontos cegos, como vimos. Por essa razão, também nosso marxismo não pode ser "calco y copia”. Para ser crítico ele deve ser "criação heróica”.

Recebido em 2.6.2009

Aprovado em 23.9.2009

\section{Referências}

ANDERSON, P. Considerações sobre o marxismo ocidental. Nas trilhas do materialismo histórico. São Paulo: Boitempo, 2004.

CARDOSO, F.H. "Teoria de dependência" ou análises concretas de situações de dependência. In: $\mathbf{O}$ modelo político brasileiro. São Paulo: Difusão Européia do Livro, 1972, p. 123-139.

CARDOSO, F.H. \& SERRA, J. As desventuras da dialética da dependência. Estudos Cebrap, n. 23, p. 34-80, 1979.

CARDOSO, F.H. \& FALETTO, E. Dependência e desenvolvimento na América Latina: ensaio de interpretação sociológica. Rio de Janeiro: Civilização Brasileira, 2004.

COGGIOLA, O. A agonia da tradição crítica brasileira e latinoamericana. Crítica Marxista, São Paulo, n. 20, p. 90-110, 2005.

COONEY, P. Towards and empirical measure of international transfers of value. In: FREEMAN, A.; KLIMAN, A. \& WELLS, J. The New Value Controversy and the Foundations of Economics. Cheltenham: Edward Elgar, 2004, p. 241-260.

DUSSEL, E. El último Marx (1863-1882) y la liberación latinoamericana. México D.F.: Siglo XXI, 1990.

MARIÁTEGUI, J. Ideologia y politica. Lima: Amauta, 1987. (Obras completas, v. 13)

MARINI, R. Dialética da dependência. Petrópolis: Vozes/Clacso, 2000.

MARX, K. Le capital. Paris: M. Lachâtre, 1872. 
. Capital. Londres: Penguin, 1990, 3v.

MARX, K. \& ENGELS, F. Werke: Herausgege ben vom Institut fuir Marxismus-Leninismus beim ZK der SED. Berlin: Dietz-Verlag, 1956 ff. (Citado como MEW).

. Collected works. Nova York: International Publisher, 1976ss. (Citado como MECW).

MANDEL, E. O capitalismo tardio. São Paulo: Abril Cultural, 1982.

MATTOS, M. Em busca da revolução socialista: a trajetória da Polop (1961-967). In: RIDENTI, Marcelo e REIS FILHO, Daniel Aarão. História do marxismo no Brasil: partidos e organizações dos anos 20 aos 60. Campinas: Unicamp, 2002, v. 5, p. 185-212.

MONJARÁS-RUIZ, J. México em los escritos y fuentes de Karl Marx. Nueva Sociedad, n. 66, p. 105-111, 1983.

MORAES, J. Le statut theorique de la notion de dependence. VVAA. Dependencia y estructura de clase em America Latina. Genebra: Centre Europe-Tiers Monde, 1972.

MORENO, N. Cuatro tesis sobre la colonización española y portuguesa em América. Estratégia, Buenos Aires, n. 1, 1957.

PCB. Declaração sobre a política do PCB. Voz Operária, 22 mar. 1958. In: CARONE, Edgar. O PCB (1943-1964). São Paulo: Difel, 1982.

PEDROSA, M. \& XAVIER, L. Esboço de uma análise da situação econômica e social do Brasil. ABRAMO, Fúlvio e KAREPOVS, Dainis. Na contracorrente da história: documentos da Liga Comunista internacionalista (1930-1933). São Paulo: Brasiliense, 1987.

PEÑA, M. Antes de Mayo. Buenos Aires: Fichas, 1975.

. El paraíso terrateniente. Buenos Aires: Fichas, 1975a. . La era de Mitre. Buenos Aires: Fichas, 1975b. . De Mitre a Roca. Buenos Aires: Fichas, 1975c. . Alberdi, Sarmiento y el 90. Buenos Aires: Fichas, 1975d. . Masas caudillos y elites. Buenos Aires: Fichas, 1975e. . Indústria, burguesia industrial y liberación nacional. Buenos Aires: Fichas, 1974. 
SADER, E. Nós que amávamos tanto O Capital: fragmentos para a história de uma geração. In: $\mathbf{O}$ poder, cadê o poder? Ensaios para uma nova esquerda. São Paulo: Boitempo, 1997, p. 87-111.

SALLUM Jr., B. Notas sobre o surgimento da Sociologia Política em São Paulo. Política \& Sociedade, v. 1, n. 1, 2002.

SCHWARZ, R. Seqüiências brasileiras: ensaios. São Paulo: Companhia das Letras, 1999.

SERRA, J. \& CARDOSO, F.H. As desventuras da dialética da dependência. Estudos Cebrap, 1979.

SHAIKH, A. Valor, acumulación y crisis: ensayos de economia política. Bogotá: Tercer Mundo, 1991.

WEFFORT, F. Dependência: teoria de classes ou ideologia nacional? In: $\mathbf{O}$ populismo na política brasileira. Rio de Janeiro: Paz e Terra, 1989, p. 165-181.

ZEA, L. Visión de Marx sobre América Latina. Nueva Sociedad, n. 55, p. 59-66, 1983.

\section{Abstract \\ Marxism out-of-place}

This article discusses the difficulties that exist for the development of a Latin American Marxism. This difficulty may flow from Marx and Engels work itself, and the philosophy of history that emerges in several moments of this work. Nonetheless, the analysis of the situation in Ireland and of the Russian rural commune allowed these writers - and Marx in particular - to go beyond this philosophy of history. We then move on to discuss one attempt to interpret Latin America, and Brazil in particular, based on Marx`s work: one which was developed within the ambit of the "Seminário d'O Capital." In this seminar, a form of appropriating Marx's work giving salience to methodological aspects was promoted. In spite of the important contribution of the authors linked to this seminar, among them Fernando Henrique Cardoso and his analysis of situations of dependence, this appropriation of Marx`s work revealed clear limitations. Thus, we end with an argument on the need for Marxism to build a deep link between theory and practice, theoretical and empirical research in order to go beyond existing impasses in the interpretation of Latin America.

Keywords: Marxism, Dependency Theory, unequal exchange, Latin America. 
